\title{
An Analysis of the Educational and Health-Related Benefits of Nature-Based Environmental Education in Low-Income Black and Hispanic Children
}

Nadav Sprague, ${ }^{1,2}$ David Berrigan, ${ }^{2}$ and Christine C. Ekenga ${ }^{1, *}$

\begin{abstract}
Background: Low-income and non-white children experience disparities in health, education, and access to nature. These health disparities are often associated and exacerbated by inequities in the U.S. educational system. Recent research suggests that nature contact may reduce these health and educational disparities for urban lowincome populations. Nature-based education (NBE) uses nature contact to inspire curiosity and improve health. This study examines the health and educational outcomes of a 15-week NBE intervention for urban low-income, black and Hispanic children 10-15 years of age.

Methods: Children $(n=122)$ completed a pre-intervention and post-intervention survey that addressed seven science, technology, engineering, and math (STEM)-capacity items (leadership, teamwork, science relevance, sustainability relevance, STEM self-efficacy, science interest, and overall STEM capacity) and six widely used health-related quality-of-life (HRQoL) domains (physical health functioning, emotional health functioning, school functioning, social functioning, family functioning, and overall HRQoL). Focus groups with participating students and postintervention surveys of NBE mentors and teachers explored perceptions of the intervention impact.

Results: There were statistically significant positive changes in STEM capacity and HRQoL for participating students. For example, children's overall STEM capacity and overall HRQoL scores improved by $44 \%$ and $46 \%$, respectively (both $p<0.05$ ). Qualitative data highlighted the intervention's educational and health benefits.

Conclusions: These results support further research quantifying the effects of NBE on STEM capacity and HRQoL in urban, low-income, black and Hispanic children.
\end{abstract}

Keywords: health-related quality of life; nature contact; environmental education; sustainability; youth; environmental justice

\section{Introduction}

Across the health spectrum, non-white and lowincome children experience health disparities. ${ }^{1}$ These childhood health disparities involve differences in health and behavioral outcomes for specific racial, ethnic, and socioeconomic populations. ${ }^{1}$ Childhood health disparities have both immediate and long-term consequences. ${ }^{2}$ These potentially lifelong consequences include increased risks for long-term adverse health outcomes (e.g., diabetes, cardiovascular disease, and cancer $)^{3-7}$ as well as establishment of negative health behaviors at an early age, which often continue into adulthood. ${ }^{8,9}$ Black and Hispanic children as well as low-income children also face educational inequalities compared to white or high-income children. ${ }^{10,11}$ Furthermore, education is an upstream social determinate of health, and programs that reduce educational inequities promote health equity. ${ }^{12}$ There are significant racial

\footnotetext{
${ }^{1}$ Brown School, Washington University in St. Louis, St. Louis, Missouri, USA.

${ }^{2}$ Division of Cancer Control and Population Sciences, National Cancer Institute, Bethesda, Maryland, USA.
}

*Address correspondence to: Christine C. Ekenga, PhD, MPH, Brown School, Washington University in St. Louis, One Brookings Drive, Campus Box 1196, St. Louis, MO 63130, USA, E-mail: ekengac@wustl.edu

(C) Nadav Sprague et al. 2020; Published by Mary Ann Liebert, Inc. This Open Access article is distributed under the terms of the Creative Commons License (http://creativecommons.org/licenses/by/4.0), which permits unrestricted use, distribution, and reproduction in any medium, provided the original work is properly cited. 
and socioeconomic disparities in access to and contact with nature. ${ }^{13-16}$ White children have significantly more nature contact than black children. ${ }^{17}$ Recent attention has focused on the potential role of nature contact as an influence on health disparities for urban low-income populations. ${ }^{15}$

There is a growing body of evidence that suggests that nature contact is a practical method for promoting better physical, emotional, mental, and overall health for children as young as 10 years. ${ }^{18-21}$ Childhood nature contact promotes positive youth development, improved cognition, childhood resilience, and reduction of mental health disorders (e.g., anxiety, depression, and attention deficit hyperactivity disorder $[\mathrm{ADHD}])^{22-26}$ Both crosssectional and prospective cohort studies have found that increased childhood nature contact is positively associated with increased physical activity. ${ }^{21,27-29}$ Furthermore, a few studies have found greater physical and mental health benefits from green exercise (outdoor physical activities in natural settings) than traditional forms of exercise. ${ }^{30-33}$

\section{Nature-based education}

Nature-based education (NBE) is a form of environmental education that uses nature contact to increase environmental awareness and inspire curiosity. ${ }^{29,33}$
Our conceptual model of NBE's impacts on healthrelated quality of life (HRQoL) and science, technology, engineering, and math (STEM) knowledge (Fig. 1) represents a synthesis of the emerging research on environmental education and pathways through which it might benefit children, ${ }^{34}$ along with potential pathways through which nature contact may promote positive health outcomes. ${ }^{29,35,36}$ In this model, NBE may increase STEM knowledge, which is associated with increased self-esteem and family cohesion for lowincome and non-white children ${ }^{37,38} \mathrm{NBE}$ interventions may improve children's academic success, which influences childhood HRQoL. ${ }^{39,40}$ In addition, NBE incorporates nature-contact components, increasing the frequency of nature contact and its benefits. ${ }^{24,29,36,41}$

A pilot study found that this NBE intervention significantly improved overall HRQoL scores and family support HRQoL domain scores for low-income, black and Hispanic children in St. Louis, Missouri. ${ }^{42}$ In this study, we investigate how NBE influences health and educational outcomes for low-income, black and Hispanic children in St. Louis, MO, USA. This study includes a larger sample of students, a further examination of STEM-capacity, and qualitative aspects of the response to the NBE intervention in students, teachers, and

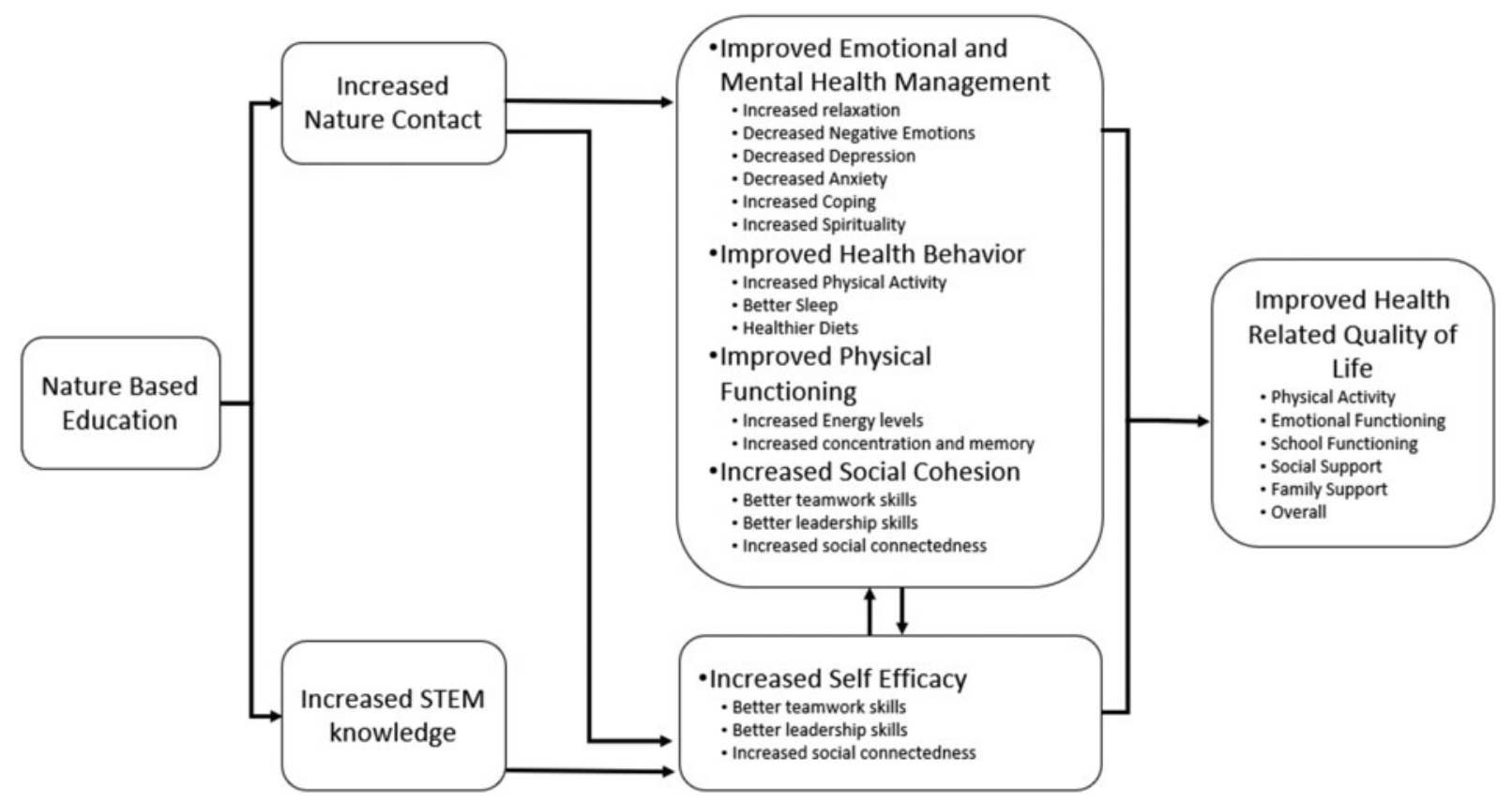

FIG. 1. Conceptual model of NBE impacts on HRQoL and STEM knowledge. HRQoL, health-related quality of life; NBE, nature-based education; STEM, science, technology, engineering, and math. 
NBE mentors. Our study tests the hypothesis that an NBE intervention improves two outcomes: (1) HRQoL and (2) STEM knowledge and self-efficacy (STEM capacity).

\section{Methods}

NBE intervention

A NBE intervention was developed for low-income black and Hispanic children in St. Louis, Missouri. The intervention was administered to three elementary and middle schools in the St. Louis Public Schools District (SLPS) during the 2018-2019 academic year. SLPS is the largest urban public school district in the St. Louis metropolitan area. ${ }^{43}$ In the 2018-2019 school year, SLPS had an enrollment of 20,879 students; $80 \%$ of whom were black and $4 \%$ Hispanic. ${ }^{43}$ The SLPS district faces welldocumented and significant educational inequalities compared to neighboring school districts. ${ }^{44-46}$ For example, in the 2018 statewide standardized assessment, only $23 \%$ of SLPS students scored proficient or advanced in the English and Language Arts section and only 19\% scored proficient or advanced on the Math section compared to the greater St. Louis metropolitan area averages of $47 \%$ and $41 \%$, respectively. ${ }^{43}$ To qualify for the NBE intervention, schools were required to have more than $95 \%$ of the student body eligible for free or reduced meals through the National School Lunch Program and the School Breakfast Program.

The NBE intervention was facilitated by Gateway to the Great Outdoors, a regional nonprofit organization founded by one of the investigators (N.S.). ${ }^{47}$ The NBE intervention consisted of weekly STEM-based environmental education classroom lessons and monthly nature-based outdoor field trips facilitated by volunteer undergraduate mentors (NBE mentors). The NBE mentors were recruited, trained, and overseen by the nonprofit organization. Every week, the NBE mentors would visit their assigned SLPS classroom and teach interactive lessons created by the nonprofit organization, based on the classroom's STEM curricula, the state of Missouri's Testing Standards, ${ }^{48}$ EPA lesson plans, ${ }^{49}$ Next Generation Science Standards, ${ }^{50}$ and other environmental science courses. The nature-based outdoor field trips were created to provide context for classroom activities and reinforce classroom learning. In conjunction, the weekly in-class environmental education lessons and monthly nature-based field trips were developed to promote teamwork, leadership, environmental and conservation awareness, STEM knowledge, and improved HRQoL, while also teaching outdoor skills and changing SLPS students' perceptions of science and sustainability. Table 1 provides an overview of the interventions' curricula, monthly field trips, and learning objectives.

The average duration of the intervention was 15 weeks. Data from the SLPS students were collected through a pre-intervention survey in January 2019 and a post-intervention survey in May 2019 (Spring semester 2019). Qualitative data, from the focus groups, were collected in April 2019. Data from the SLPS schoolteachers and NBE mentors were collected through a post-intervention survey in May 2019. Washington University in St. Louis's Institutional Review Board deemed this study as exempt from review since the data were anonymous.

\section{Quantitative analysis}

The study used a pre-test-post-test study design to evaluate HRQoL and STEM capacity during the NBE intervention. A self-administered 22-item survey was distributed to the SLPS students before participating in the intervention (pre-intervention) and after completing the intervention (post-intervention). The survey collected information about age, gender, race, and past STEM and nature contact experiences before entering the intervention. The pre-interventionpost-intervention survey consisted of five widely used, validated, HRQoL domains (physical health functioning, emotional health functioning, school functioning, social functioning, and family functioning $)^{51-53}$ and six STEM-capacity domains (leadership, teamwork, science relevance, sustainability relevance, STEM self-efficacy, and science interest). The STEM-capacity instrument was informed by current STEM education literature as well as input from the SLPS teachers. ${ }^{34,54-59}$ Responses to the HRQoL domains were assessed using 5-point Likert-type scales ranging from 1 to 5 , and responses to the STEM-capacity domains were assessed using a 3-point Likert-type scale ranging from 1 to 3. Lower scores indicated better HRQoL and STEM capacity.

HRQoL and STEM-capacity items were reversescored so that higher scores indicated better HRQoL and STEM capacity, respectively. An overall HRQoL score and an overall STEM-capacity score were determined by summing the respected domain scores. Preintervention-post-intervention differences in STEM capacity and HRQoL were assessed using independent t-tests. Linear regression models were used to assess each HRQoL and STEM-capacity domain score by age, gender, and duration in the intervention. 


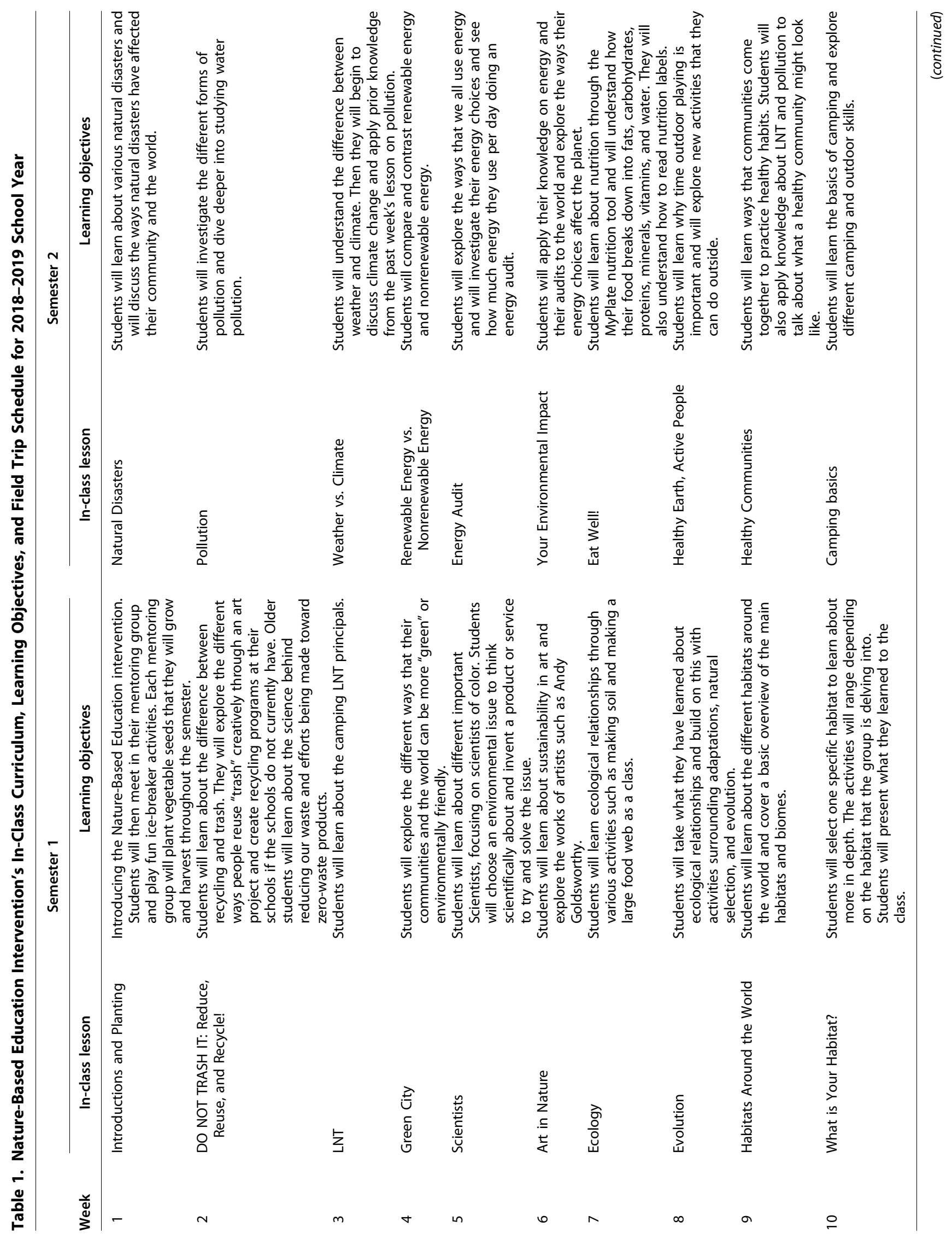




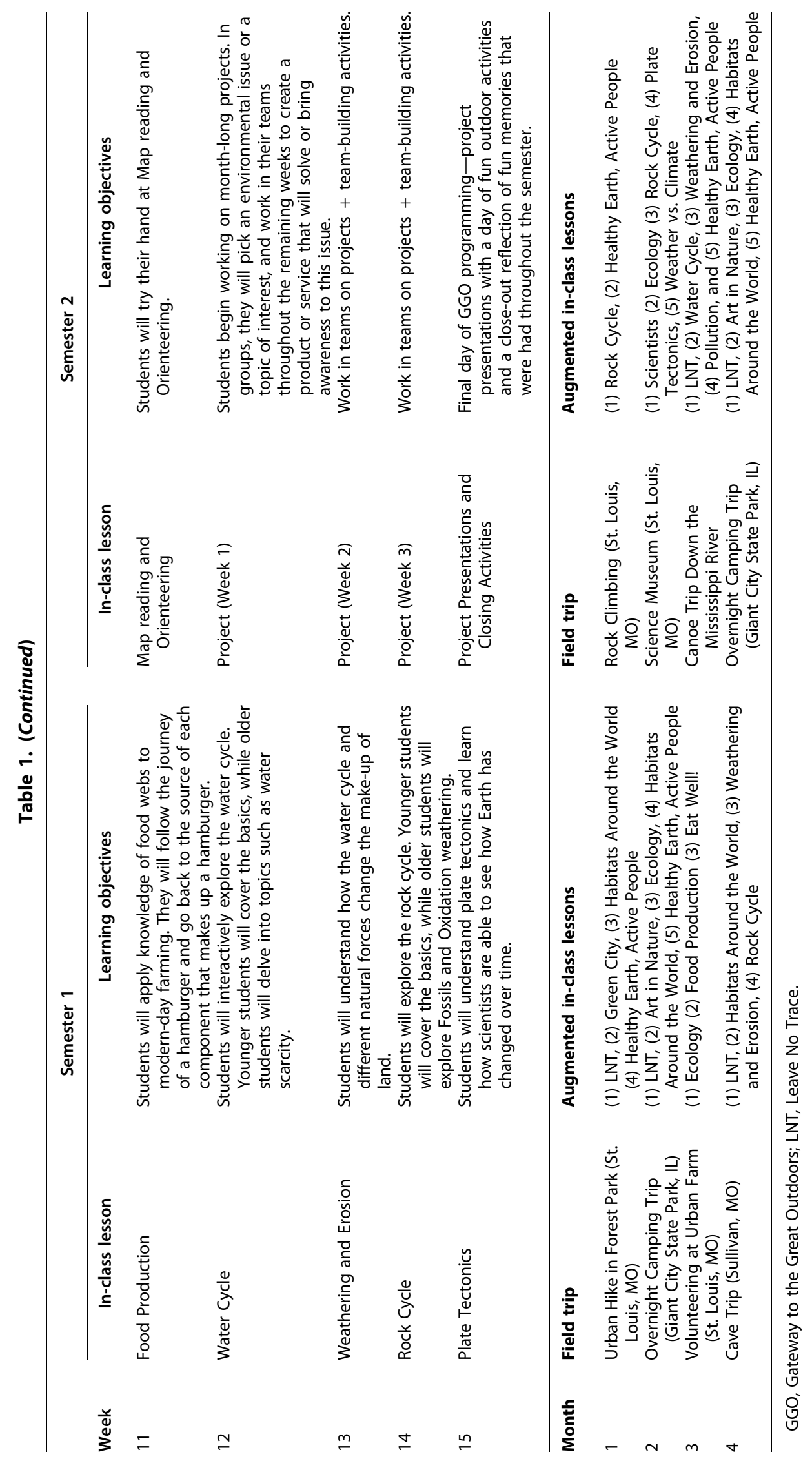




\section{Qualitative analysis}

To provide additional qualitative data, a focus group was held for each classroom participating in the NBE intervention. These focus groups were incorporated into the intervention to provide a more holistic insight into the NBE intervention's impact on the HRQoL and STEM capacity. ${ }^{17,60}$ The study completed 10 focus groups to collect qualitative data on the SLPS students' engagement, learning outcomes, and experience with the NBE intervention. Focus groups composed of 1025 children who participated in the NBE intervention. The moderator posed predetermined questions to participants, added questions to probe answers, and assured that the discussion remained on the subject of interest. The focus group discussions lasted $\sim 30 \mathrm{~min}$. Focus group discussions were taped and transcribed.

We used Braun and Clarke's method to analyze the major themes appearing in the focus groups. ${ }^{61,62} \mathrm{We}$ identified the themes as they appeared, while reviewing the data, rather than analysis based on an existing theoretical framework. First, three trained reviewers conducted an initial review of the transcribed focus groups to familiarize themselves. Then, the reviewers independently generated potential themes to code. The three reviewers evaluated the potential themes and reached consensus on a final set of themes. One reviewer then coded the transcribed focus groups based on the finalized themes. Quotes that contained multiple themes were coded with more than one theme. The distribution of themes per focus group was determined and the reviewers selected representative quotes for each theme.

\section{NBE mentors' and schoolteachers'}

\section{perceptions analysis}

After completion of the course NBE mentors and schoolteachers completed a 17 -item post-intervention survey. The survey collected information on their perceptions of the NBE intervention impact on the SLPS students. The survey administered to the NBE mentors and the schoolteachers was summarized with univariate analyses. For the open ended section of the post-survey, we used Braun and Clarke's method described above to identify the major themes of the interviews. ${ }^{61,62}$

\section{Results}

Participant characteristics

A total of 122 SLPS students participated in the NBE intervention during the Spring semester 2019. Children's ages ranged from 10 to 15 years. Each participant completed the pre-intervention survey and all but two
Table 2. Demographic Distribution of St. Louis Public School Student Participants $(n=122)$

\begin{tabular}{|c|c|c|c|c|}
\hline & Total & School 1 & School 2 & School 3 \\
\hline $\begin{array}{l}\text { Grade levels } \\
\text { participating }\end{array}$ & & $\begin{array}{l}\text { Sixth, seventh, } \\
\text { eighth }\end{array}$ & Sixth & Fifth \\
\hline Average age (SD) & $11.9(1.0)$ & $12.9(0.9)$ & $11.6(0.5)$ & $11.1(0.9)$ \\
\hline $\begin{array}{l}\text { Average semesters } \\
\text { in program (SD) }\end{array}$ & $1.7(1.1)$ & $2.6(1.5)$ & $1(0.0)$ & $2(0.0)$ \\
\hline \multicolumn{5}{|l|}{ Gender } \\
\hline $\mathrm{M}$ & 61 & 19 & 29 & 13 \\
\hline $\mathrm{F}$ & 61 & 18 & 32 & 11 \\
\hline \multicolumn{5}{|l|}{ Ethnicity } \\
\hline Non-Hispanic Black & 102 & 31 & 48 & 23 \\
\hline Hispanic Black & 16 & 5 & 10 & 1 \\
\hline Other $^{\mathrm{a}}$ & 4 & 1 & 3 & 0 \\
\hline Total & 122 & 37 & 61 & 24 \\
\hline
\end{tabular}

${ }^{a}$ Other includes one white Hispanic, one white non-Hispanic, one American Indian or Alaska Native, and one Asian.

completed the post-intervention survey. Table 2 displays the demographic distribution of the participants.

During the Spring 2019 semester, 68 of the 122 children participated in the intervention for the first time. In the year before the intervention, of these 68 participants, $54 \%$ had not visited a zoo, $46 \%$ had not visited a museum, $27 \%$ had not visited a park, 53\% had not visited a garden, and $74 \%$ had not met a scientist (Fig. 2).

\section{Health-related quality of life}

We saw significant improvements in all HRQoL domain (physical health functioning, emotional health functioning, school functioning, social functioning, family functioning, and overall HRQoL) mean and median scores from pre-intervention to post-intervention (all $p<0.05$ ). We further tested the interactions between age, gender, and duration in the intervention with the pre-intervention to post-intervention scores for each HRQoL domain. There was no significant interaction between gender and duration in the intervention with the pre-intervention and post-intervention mean and median HRQoL domain scores (all $p>0.05$ ). For age, interactions were significant for the physical health domain $(p=0.019)$, social functioning domain $(p=0.005)$, and overall HRQoL domain $(p=0.001)$. Therefore, the results presented are stratified by age in Table 3.

Age was not a significant interaction variable for emotional health functioning, school functioning, or family functioning HRQoL domains (all $p>0.10$ ). The mean emotional health functioning HRQoL domain score increased from 2.4 in the pre-intervention survey to 4.1 in the post-intervention survey $(p<0.001)$. The 


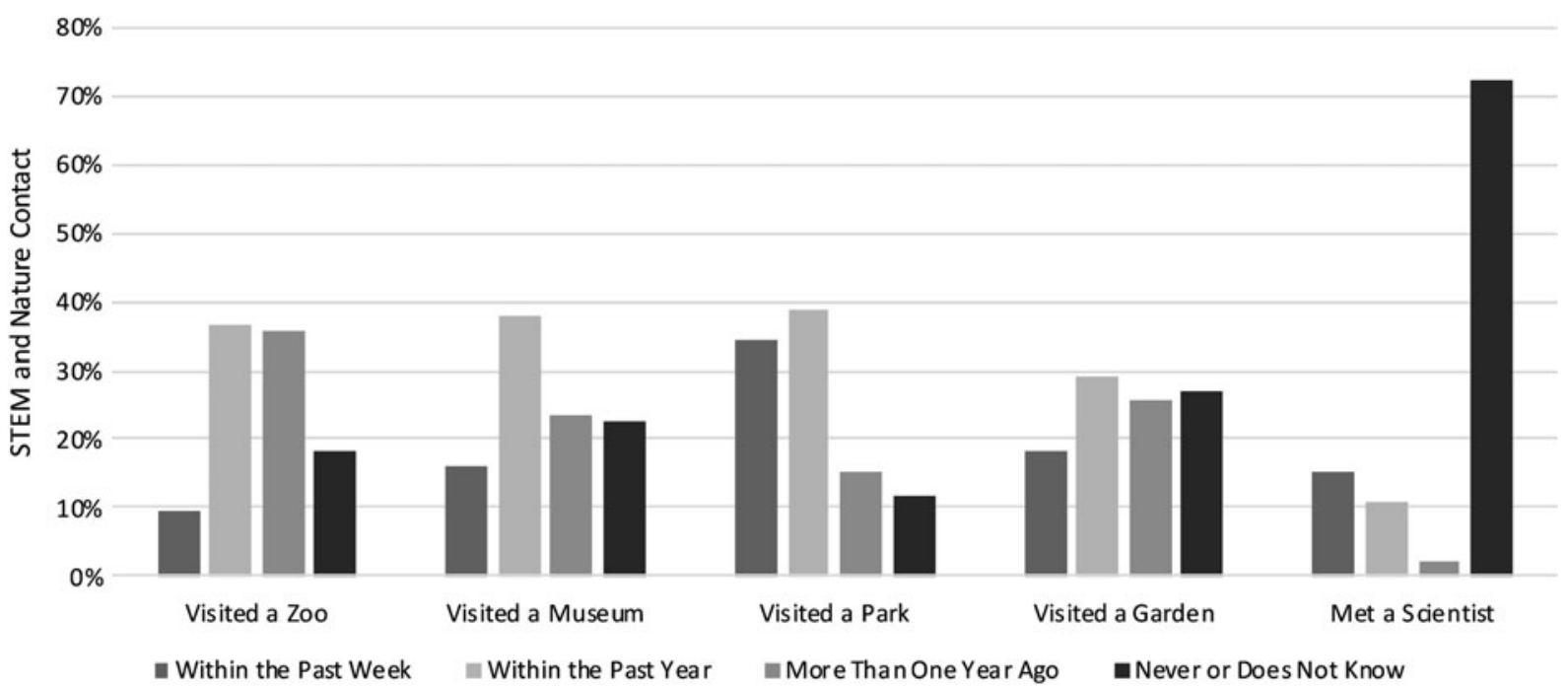

FIG. 2. SLPS students' STEM and nature contact before the education intervention $(n=68)$. SLPS, St. Louis Public School.

mean school functioning HRQoL domain score increased from 3.1 in the pre-intervention to 4.2 in the post-intervention $(p<0.001)$. The family functioning HRQoL domain mean score rose from 2.1 to 2.9 after the NBE intervention $(p=0.001)$.

\section{STEM capacity}

We tested the interactions between age, gender, and duration in the intervention with the pre-intervention to post-intervention scores for each STEM-capacity domain. There was no significant interaction between age and gender with the pre-intervention and postintervention mean and median domain scores (all $p>0.05)$. For duration in the intervention, there were significant interactions for all STEM-capacity domain scores. Therefore, we present the results stratified by duration in the intervention in Table 4. Each STEMcapacity domain (leadership, teamwork, science relevance, sustainability relevance, STEM self-efficacy, science interest, and overall STEM-capacity) mean and median score significantly increased from preintervention to post-intervention (all $p<0.05$ ).

Table 3. Health-Related Quality-of-Life Scores Pre-Intervention and Post-Intervention, Stratified by Age $(n=120)$

\begin{tabular}{|c|c|c|c|c|c|c|c|c|c|}
\hline \multirow[b]{2}{*}{ HRQoL } & \multicolumn{2}{|c|}{ Overall } & \multicolumn{2}{|c|}{ Eleven and under } & \multicolumn{2}{|c|}{ Twelve } & \multicolumn{2}{|c|}{ Thirteen and older } & \multirow[b]{2}{*}{$\begin{array}{c}\text { Interaction } \\
p \text {-value }\end{array}$} \\
\hline & $\begin{array}{c}\text { Pre- } \\
\text { intervention } \\
\text { score (SD) }\end{array}$ & $\begin{array}{c}\text { Post- } \\
\text { intervention } \\
\text { score (SD) }\end{array}$ & $\begin{array}{c}\text { Pre- } \\
\text { intervention } \\
\text { score (SD) }\end{array}$ & $\begin{array}{c}\text { Post- } \\
\text { intervention } \\
\text { score (SD) }\end{array}$ & $\begin{array}{c}\text { Pre- } \\
\text { intervention } \\
\text { score (SD) }\end{array}$ & $\begin{array}{c}\text { Post- } \\
\text { intervention } \\
\text { score (SD) }\end{array}$ & $\begin{array}{c}\text { Pre- } \\
\text { intervention } \\
\text { score (SD) }\end{array}$ & $\begin{array}{c}\text { Post- } \\
\text { intervention } \\
\text { score (SD) }\end{array}$ & \\
\hline $\begin{array}{l}\text { Physical health } \\
\text { functioning }\end{array}$ & $3.3(1.4)$ & $4.5(1.2)$ & $3.7(1.5)$ & $4.0(1.4)$ & $3.1(1.4)$ & $4.5(1.1)$ & $3.1(1.4)$ & $4.4(1.1)$ & 0.019 \\
\hline $\begin{array}{l}\text { Emotional health } \\
\text { functioning }\end{array}$ & $2.4(1.2)$ & $4.1(0.9)$ & $2.6(1.7)$ & $4.0(1.0)$ & $2.3(0.9)$ & $4.2(0.9)$ & $2.2(1.2)$ & $4.2(0.7)$ & 0.206 \\
\hline $\begin{array}{l}\text { School } \\
\quad \text { functioning }\end{array}$ & $3.1(1.3)$ & $4.2(0.9)$ & $3.5(1.3)$ & $4.2(0.9)$ & $2.9(1.3)$ & $4.2(1.0)$ & $3.1(1.3)$ & $4.3(0.8)$ & 0.141 \\
\hline $\begin{array}{l}\text { Social } \\
\quad \text { functioning }\end{array}$ & $2.6(1.2)$ & $4.1(0.1)$ & $3.2(1.2)$ & $3.9(1.2)$ & $2.42(1.1)$ & $4.2(1.0)$ & $2.2(1.2)$ & $4.0(1.1)$ & 0.005 \\
\hline $\begin{array}{l}\text { Family } \\
\quad \text { functioning }\end{array}$ & $2.1(1.3)$ & $3.0(1.6)$ & $2.2(1.4)$ & $2.9(1.5)$ & $1.9(1.3)$ & $2.9(1.6)$ & $2.2(1.2)$ & $3.1(1.5)$ & 0.829 \\
\hline $\begin{array}{l}\text { Overall } \\
\text { HRQoL }\end{array}$ & $13.5(3.7)$ & $19.9(2.8)$ & $15.2(4.2)$ & $18.8(3.1)$ & $12.6(3.1)$ & $19.9(2.9)$ & $12.8(3.4)$ & $19.9(2.8)$ & 0.001 \\
\hline
\end{tabular}

Bold type indicates statistically significance.

HRQoL, health-related quality of life 
Table 4. Science, Technology, Engineering, and Math-Capacity Scores Pre-Intervention and Post-Intervention, Stratified by Learning Duration $(n=120)$

\begin{tabular}{|c|c|c|c|c|c|c|c|}
\hline \multirow[b]{2}{*}{ STEM capacity } & \multicolumn{2}{|c|}{ Overall } & \multicolumn{2}{|c|}{ First semester } & \multicolumn{2}{|c|}{ Two or more semesters } & \multirow[b]{2}{*}{$\begin{array}{l}p \text {-Value of } \\
\text { interaction }\end{array}$} \\
\hline & $\begin{array}{c}\text { Pre- } \\
\text { intervention } \\
\text { score (SD) }\end{array}$ & $\begin{array}{c}\text { Post- } \\
\text { intervention } \\
\text { score (SD) }\end{array}$ & $\begin{array}{c}\text { Pre- } \\
\text { intervention } \\
\text { score (SD) }\end{array}$ & $\begin{array}{c}\text { Post- } \\
\text { intervention } \\
\text { score (SD) }\end{array}$ & $\begin{array}{c}\text { Pre- } \\
\text { intervention } \\
\text { score (SD) }\end{array}$ & $\begin{array}{l}\text { Post- } \\
\text { intervention } \\
\text { score (SD) }\end{array}$ & \\
\hline Leadership & $1.3(0.8)$ & $1.7(0.5)$ & $1.1(0.8)$ & $1.7(0.4)$ & $1.6(0.7)$ & $1.8(0.5)$ & 0.004 \\
\hline Teamwork & $1.3(0.7)$ & $1.6(0.5)$ & $1.0(0.7)$ & $1.5(0.6)$ & $1.5(0.6)$ & $1.7(0.5)$ & 0.023 \\
\hline Science relevance & $1.4(0.7)$ & $1.7(0.5)$ & $1.2(0.7)$ & $1.7(0.5)$ & $1.6(0.6)$ & $1.8(0.4)$ & 0.026 \\
\hline Sustainability relevance & $0.9(0.8)$ & $1.8(0.5)$ & $0.6(0.8)$ & $1.8(0.4)$ & $1.3(0.7)$ & $1.7(0.5)$ & $<0.001$ \\
\hline STEM self-efficacy & $1.0(0.8)$ & $1.7(0.5)$ & $0.8(0.8)$ & $1.7(0.5)$ & $1.2(0.8)$ & $1.7(0.6)$ & 0.001 \\
\hline Science interest & $1.2(0.7)$ & $1.5(0.6)$ & $1.1(0.7)$ & $1.6(0.5)$ & $1.4(0.7)$ & $1.4(0.7)$ & 0.005 \\
\hline Overall STEM capacity & $7.0(2.8)$ & $10.1(1.7)$ & $5.8(2.6)$ & $10.1(1.6)$ & $8.5(2.1)$ & $10.0(1.7)$ & $<0.001$ \\
\hline
\end{tabular}

Bold type indicates statistically significance.

STEM, science, technology, engineering, and math.

\section{Qualitative results}

The thematic analysis of the focus groups revealed seven major themes: Engaging Learning Environment (26\% of the themes), Promoting Environmentally Conscious Decisions (39\%), Family Engagement (6\%), Promoting Healthy Behaviors (6\%), Promoting Physical Activity (9\%), Leadership and Team Building Skill Development (4\%), and Academic Support and Mentorship (10\%). Figure 3 shows the distributions of the themes by school and overall.
Table 5 displays each theme with representative quotes from the focus groups.

\section{NBE mentor and schoolteacher perceptions} of impact

A total of 49 NBE mentors and 5 schoolteachers completed a post-survey on their perceptions of the NBE impacts on the SLPS students. Every NBE mentor and SLPS teacher indicated that the NBE intervention was beneficial for the SLPS students. Answers to why

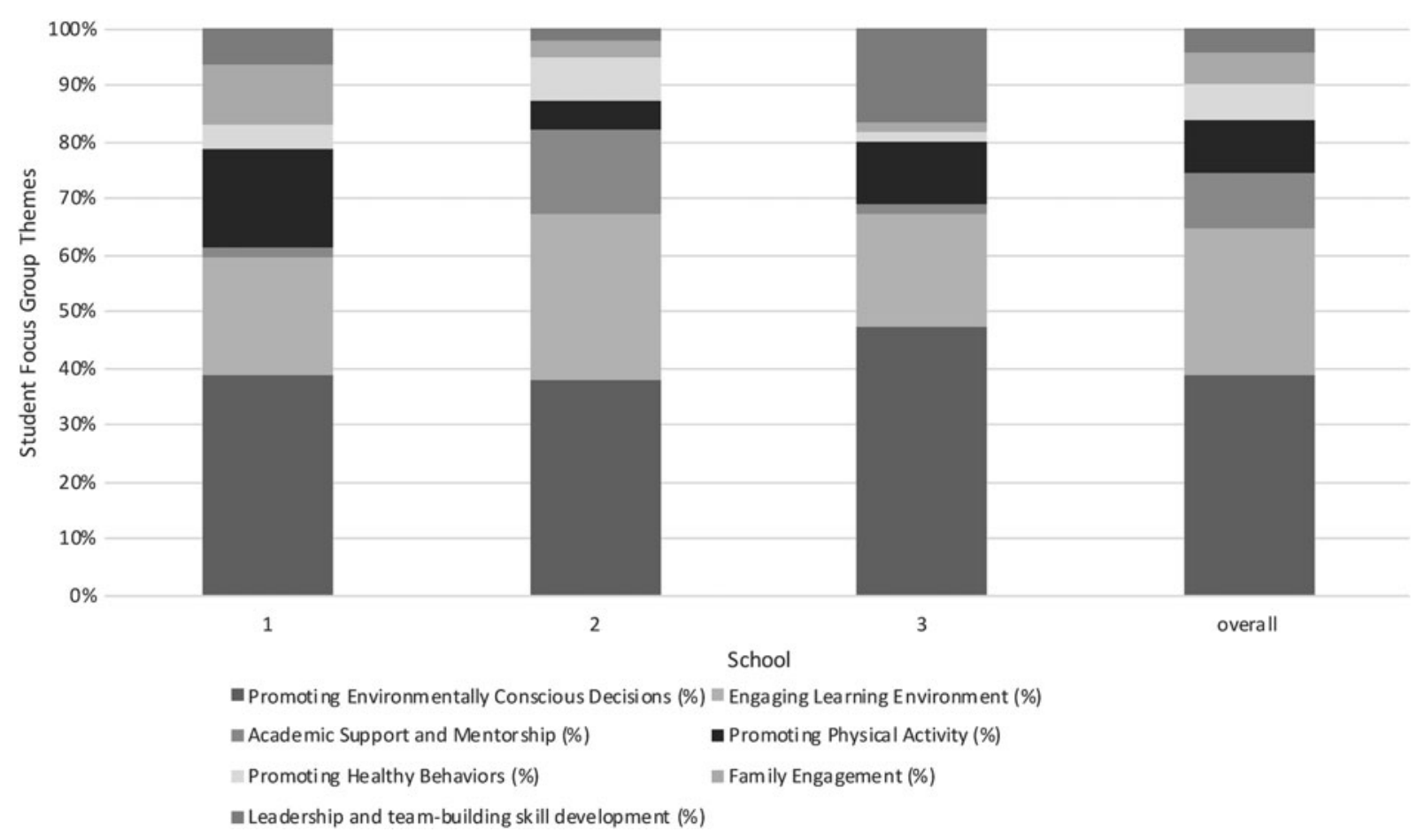

FIG. 3. Theme distribution from SLPS student focus groups by school. 
Table 5. Examples of Quotes from St. Louis Public School Student Focus Groups by Theme

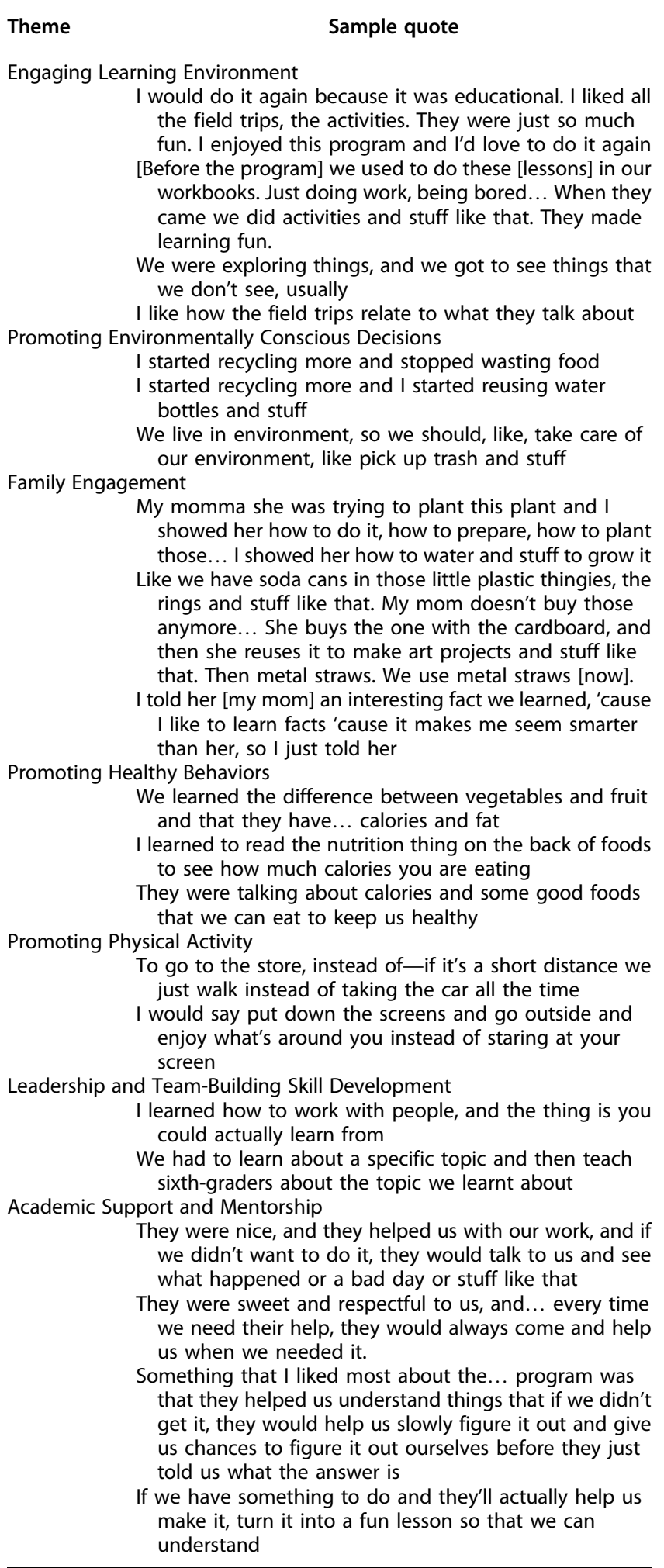

the NBE intervention was beneficial for the children varied; however, four major themes appeared: (1) Enriched Educational Experiences, (2) Increased Environmental Awareness, (3) Novel Experiences, and (4) Behavioral Change. Table 6 displays each theme with representative quotes.

Figure 4 shows the NBE mentors' and schoolteachers' perceptions of NBE's impact on the SLPS students. Approximately $98 \%$ of NBE mentors and schoolteachers agreed or strongly agreed that NBE helped the SLPS students better grasp scientific topics, $83 \%$ agreed that NBE helped the SLPS students' mental well-being, 72\% agreed that NBE helped with the SLPS students' physical well-being, $72 \%$ believed that NBE taught the SLPS students leadership skills, and $87 \%$ agreed or strongly agreed that NBE taught the SLPS students teamwork skills.

\section{Discussion}

This study evaluated an NBE intervention's influence on the HRQoL and STEM capacity for low-income, urban, black and Hispanic children. We observed significantly higher scores in every HRQoL and STEM-capacity domain after the completion of the intervention. These findings are consistent with a growing body of evidence that nature contact and environmental education improve health outcomes and scientific engagement ${ }^{29,34,63,64}$ and supports future research with stronger study designs addressing NBE as a sustainable method to reducing health and educational disparities for low-income, urban, black and Hispanic youth.

We found significant interactions with age and the improvement in the physical health functioning, social functioning, and overall HRQoL domain scores; older children (12-15 years of age) had larger improvements from the intervention than younger children (10-11 years of age). The older children had lower physical health functioning HRQoL pre-intervention scores than the younger children. This could be caused by the well-documented decline in physical activity for children during the transition from elementary to middle school. ${ }^{65}$ In addition, there is a large body of evidence that suggests children experience increased social problems and decreased HRQoL before and during middle school. ${ }^{66,67}$ This might account for the lower pretest scores we observed in older children for social functioning and overall HRQoL domains. After the intervention, all three age brackets had approximately the same social functioning and overall HRQoL 
Table 6. Examples of St. Louis Public School Teacher and Nature-Based Education Mentor Responses to "Why Was the Nature-Based Education Intervention Beneficial to Your Students?"

\begin{tabular}{|c|c|c|c|c|}
\hline Theme & Sample quote & School & $\begin{array}{l}\text { Grade } \\
\text { working } \\
\text { with }\end{array}$ & Position \\
\hline \multicolumn{5}{|c|}{ Enriched Educational Experience } \\
\hline & $\begin{array}{l}\text { NBE makes students love science and look forward to practicing science, reading, and writing. } \\
\text { It allows students to think outside of the classroom. }\end{array}$ & 1 & 8 & SLPS teacher \\
\hline Increase & $\begin{array}{l}\text { It gives the students to learn in a fun and interactive way. } \\
\text { Environmental }\end{array}$ & 2 & 6 & NBE mentor \\
\hline & $\begin{array}{l}\text { NBE both teaches them environmental information that they may not be getting in their } \\
\text { normal classes, makes them think about the world in a different way, and gives them a } \\
\text { break from normal schoolwork in the day. }\end{array}$ & 2 & 6 & NBE mentor \\
\hline & $\begin{array}{l}\text { The students were able to learn about the environment and sustainability. This is information } \\
\text { that they otherwise might not receive in school, even though it is very important to learn } \\
\text { about. }\end{array}$ & 1 & 6 & NBE mentor \\
\hline & $\begin{array}{l}\text { The students were able to learn about the environment and sustainability. This is information } \\
\text { that they otherwise might not receive in school, even though it is very important to learn } \\
\text { about. }\end{array}$ & 2 & 6 & NBE mentor \\
\hline & $\begin{array}{l}\text { I think it's very beneficial to the students. On trips, they not only make meaningful } \\
\text { experiences, but also develop connection to the outdoors that no textbook can provide. }\end{array}$ & 3 & 5 & NBE mentor \\
\hline \multicolumn{5}{|c|}{ Novel Experiences } \\
\hline & $\begin{array}{l}\text { Yes, I think GGO is beneficial to the students because they got to see, try, and do things } \\
\text { they've never done before... It's a good experience for the students and the teachers. }\end{array}$ & 3 & 5 & SLPS teacher \\
\hline & $\begin{array}{l}\text { Most of the time what we teach them or when we go on trips, they are doing things that } \\
\text { they've never done before and seem genuinely interested. }\end{array}$ & 2 & 6 & NBE mentor \\
\hline \multicolumn{5}{|c|}{ Behavioral Change and Students Reaching Full Potential } \\
\hline & $\begin{array}{l}\text { The students have a lot to say once you get them motivated. They are very smart, and this } \\
\text { organization helps them realize their true potentials. }\end{array}$ & 2 & 6 & NBE mentor \\
\hline & $\begin{array}{l}\text { I can definitely see improvements in the students' behavior when learning inside the } \\
\text { classroom and when learning outside during field trips. }\end{array}$ & 1 & 7 & NBE Mentor \\
\hline & $\begin{array}{l}\text { A great number of students talk about how much they learn and tell me how much the } \\
\text { lessons have changed their perspectives. }\end{array}$ & 2 & 6 & NBE mentor \\
\hline
\end{tabular}

NBE, nature-based education; SLPS, St. Louis Public School.

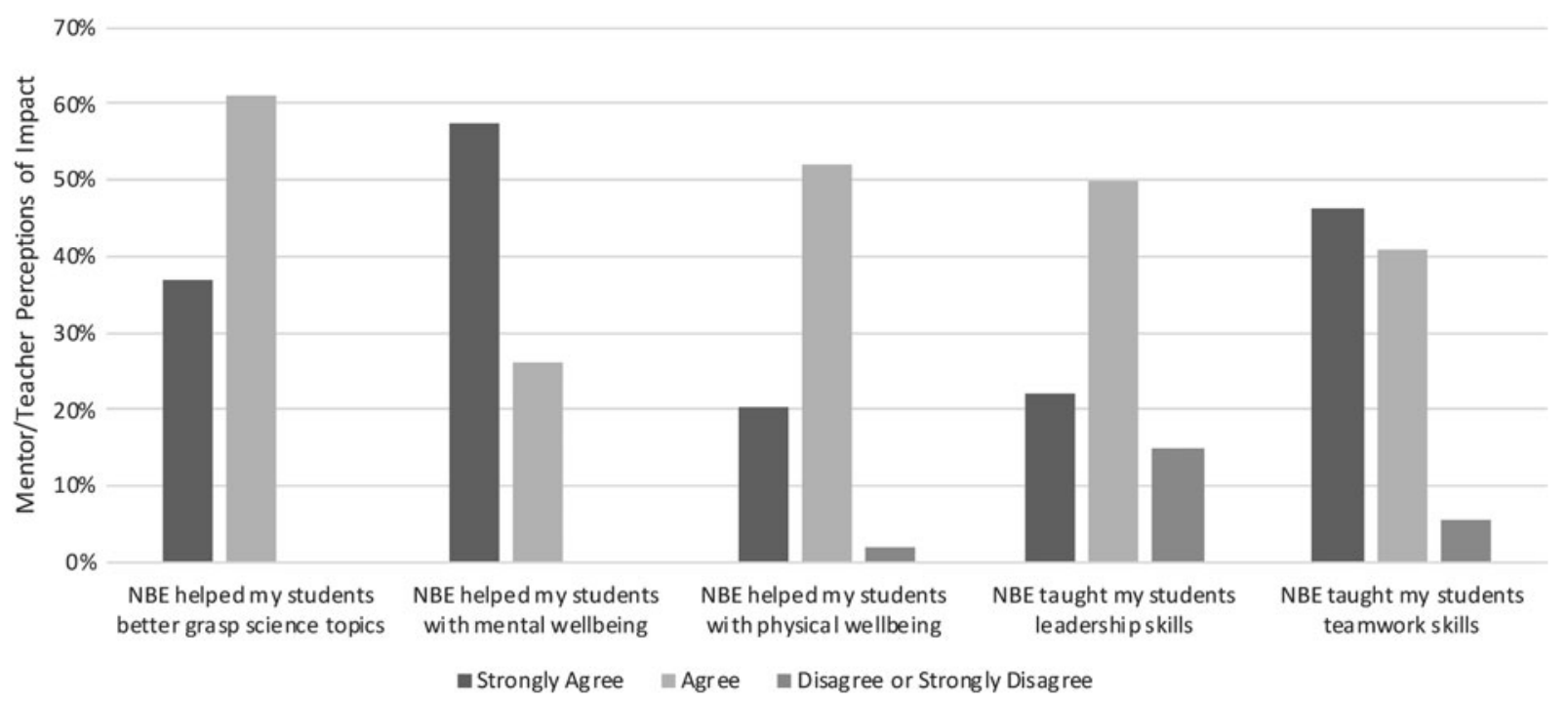

FIG. 4. NBE mentor and school teacher perception of impact. 
domain score. Similarly, a 3-year cohort study found increased time spent outdoors significantly was associated with increased physical activity and decreased obesity for older children (10 to 12 years of age), but the association was not observed in younger (5-6 years of age) children. ${ }^{21}$

We also found significant improvements in all STEM-capacity domain scores, confirming past results. ${ }^{43,68}$ Our study also found significant interactions with the duration a student participated in the intervention and the differences between the preintervention and post-intervention STEM-capacity scores, and that outdoor classes increased long-term knowledge retention for students. Together, these results support the idea that multiple years of $\mathrm{NBE}$ could increase its benefits.

There is little agreement on how to define exposure for both nature contact and environmental education. Exposure to nature includes duration, frequency, and magnitude or intensity of exposures. Currently, the majority of nature-contact exposure science studies focus on the magnitude and frequency of nature contact, not duration. ${ }^{29}$ Magnitude or intensity of exposure is also poorly quantified, but clearly, there is a range of intensities from a single plant in a hospital room to multiday wilderness camping trips. One study of adults in England found that spending at least 120 min a week in nature significantly increases the likelihood of reporting good HRQoL compared to those who had no nature contact. ${ }^{69}$ However, additional research is required to better understand the dose-response relationship between NBE and nature contact with beneficial outcomes. ${ }^{29}$

As in past studies, our thematic analysis of focus group responses revealed that NBE promotes an engaging learning environment, promotes environmentally conscious decisions, engages family, promotes healthy behaviors and physical activity, as well as develops leadership and team building skills. ${ }^{29,34}$ One study reported that NBE was a worthwhile addition to the middle school curriculum by promoting physical activity, teaching leadership and teamwork, promoting environmental stewardship, and offering relevant and memorable learning experiences. ${ }^{70}$ Our results are also consistent with these findings.

This study has several limitations. First, this developmental study had a modest sample size and duration. Second, the study population consisted of children from an urban public school system in St. Louis, Missouri, potentially reducing generalizability. Third, this study did not include a control group. Finally, our STEM-capacity instrument has not been validated, although it was based on research on the educational outcomes of environmental education.

Future research should use improved study design with the inclusion of control groups to strengthen estimates of the effects of this NBE on children's HRQoL and STEM capacity and consider longer follow-up of health and academic outcomes. In addition, results from our focus groups suggest several potential moderators of the effects of NBE, such as stressful life events. Measures of these stressors could strengthen future evaluation studies. Surveys or focus groups of the participating children's guardians on their perceptions of the NBE intervention's impact would also strengthen future studies. In the United States, educational and health disparities are often rooted in structural inequities, and additional research is needed, examining effects of the NBE in different school settings, as well as research comparing other forms of NBE (e.g., summer camps, educational programs at botanical gardens, and outdoor adventure education). The evaluation of NBE interventions in nonminority schools and in high-income public and private schools could help determine to what extent NBE reduces health and educational disparities. Future research should also explore dose-response relationships for NBE by examining interventions of different durations (e.g., 1 week, 1 month, and 1 year).

\section{Conclusion}

Our study found that low-income, urban, black and Hispanic children significantly improved their HRQoL and STEM capacity after participating in an NBE intervention in St. Louis, Missouri. These results support the need for more rigorous examination of the potential effects of this NBE intervention as a low-cost and sustainable method for improving HRQoL and STEM capacity for students at low-income schools. Larger studies with the inclusion of objective measures of behavioral and educational outcomes, a control group of students not participating in an NBE intervention, and a high-income population participating in NBE intervention will better investigate how NBE would be a feasible solution for reducing health and educational disparities.

\section{Author Disclosure Statement}

Nadav Sprague serves as the founding CEO and President of Gateway to the Great Outdoors. 


\section{Funding Information}

This work was supported, in part, by the Arlene Rubin Stiffman Junior Faculty Research Award from the Brown School at Washington University in St. Louis.

\section{References}

1. Wallander JL, Fradkin C, Elliott MN, et al. Racial/ethnic disparities in health-related quality of life and health status across pre-, early-, and midadolescence: a prospective cohort study. Qual Life Res. 2019;28:17611771.

2. Flores $G$, Res CP. Technical report-racial and ethnic disparities in the health and health care of children. Pediatrics. 2010;125:E979-E1020.

3. Holman DM, Ports KA, Buchanan ND, et al. The association between adverse childhood experiences and risk of cancer in adulthood: a systematic review of the literature. Pediatrics. 2016;138:S81-S91.

4. Zheng M, Lamb KE, Grimes $C$, et al. Rapid weight gain during infancy and subsequent adiposity: a systematic review and meta-analysis of evidence. Obes Rev. 2018;19:321-332.

5. Biro FM, Wien M. Childhood obesity and adult morbidities. Am J Clin Nutr. 2010;91:1499s-1505s.

6. Dietz WH. Health consequences of obesity in youth: childhood predictors of adult disease. Pediatrics. 1998;101:518-525.

7. Ward ZJ, Long MW, Resch SC, et al. Simulation of growth trajectories of childhood obesity into adulthood. N Engl J Med. 2017;377:2145-2153.

8. Brook DW, Brook JS, Zhang CS, et al. Developmental trajectories of cigarette smoking from adolescence to the early thirties: personality and behavioral risk factors. Nicotine Tob Res. 2008;10:1283-1291.

9. Nurius PS, Fleming CM, Brindle E. Life course pathways from adverse childhood experiences to adult physical health: a structural equation model. J Aging Health. 2019;31:211-230.

10. Bradbury B, Corak M, Waldfogel J, et al. Too Many Children Left Behind the U.S. Achievement Gap in Comparative Perspective. New York: Russell Sage Foundation, 2015.

11. Harris AL. Despite the best intentions: how racial inequality thrives in good schools. Soc Forces. 2016;95:e30.

12. Hahn RA, Truman BI. Education improves public health and promotes health equity. Int J Health Serv. 2015;45:657-678.

13. Vaughan KB, Kaczynski AT, Stanis SAW, et al. Exploring the distribution of park availability, features, and quality across Kansas city, Missouri by income and race/ethnicity: an environmental justice investigation. Ann Behav Med. 2013;45:S28-S38.

14. Schwarz K, Fragkias M, Boone CG, et al. Trees grow on money: urban tree canopy cover and environmental justice. PLoS One. 2015;10:e0122051.

15. Jennings V, Gaither CJ. Approaching environmental health disparities and green spaces: an ecosystem services perspective. Int J Environ Res Public Health. 2015;12:1952-1968.

16. Casey JA, James $P$, Cushing $L$, et al. Race, ethnicity, income concentration and 10-year change in urban greenness in the United States. Int J Environ Res Public Health. 2017;14:pii: E1546.

17. Larson LR, Castleberry SB, Green GT. Effects of an environmental education program on the environmental orientations of children from different gender, age, and ethnic groups. J Park Recreat Admi. 2010;28:95-113.

18. Bogner FX. The influence of a residential outdoor education programme to pupil's environmental perception. Eur J Psychol Educ. 2002;17:19-34.

19. Bogner FX, Wiseman M. Association tests and outdoor ecology education. Eur J Psychol Educ. 1997;12:89-102.

20. Mitchell R, Popham F. Effect of exposure to natural environment on health inequalities: an observational population study. Lancet. 2008;372: 1655-1660.

21. Cleland V, Crawford D, Baur LA, et al. A prospective examination of children's time spent outdoors, objectively measured physical activity and overweight. Int J Obes. 2008;32:1685-1693.

22. Bocarro J, Greenwood PB, Henderson KA. An integrative review of youth development research in selected United States recreation journals. J Park Recreat Admi. 2008;26:4-27.

23. Berman MG, Jonides J, Kaplan S. The cognitive benefits of interacting with nature. Psychol Sci. 2008;19:1207-1212.

24. Bratman GN, Daily GC, Levy BJ, et al. The benefits of nature experience: improved affect and cognition. Landsc Urban Plan. 2015;138:41-50.
25. Wells NM, Evans GW. Nearby nature-a buffer of life stress among rural children. Environ Behav. 2003:35:311-330.

26. Razani N, Niknam K, Wells NM, et al. Clinic and park partnerships for childhood resilience: a prospective study of park prescriptions. Health Place. 2019;57:179-185.

27. Oreskovic NM, Kuhlthau KA, Romm D, et al. Built environment and weight disparities among children in high- and low-income towns. Acad Pediatr. 2009;9:315-321.

28. Gray C, Gibbons R, Larouche R, et al. What is the relationship between outdoor time and physical activity, sedentary behaviour, and physical fitness in children? A systematic review. Int J Environ Res Public Health. 2015;12:6455-6474.

29. Frumkin $\mathrm{H}$, Bratman GN, Breslow SJ, et al. Nature contact and human health: a research agenda. Environ Health Perspect. 2017;125:075001.

30. Han KT. The effect of nature and physical activity on emotions and attention while engaging in green exercise. Urban For Urban Gree. 2017;24:5-13.

31. Mitchell R. Is physical activity in natural environments better for mental health than physical activity in other environments? Soc Sci Med. 2013;91: 130-134.

32. Coon JT, Boddy K, Stein K, et al. Does participating in physical activity in outdoor natural environments have a greater effect on physical and mental wellbeing than physical activity indoors? A systematic review. Environ Sci Technol. 2011;45:1761-1772.

33. Schweitzer JP, Gionfra S. Nature-based education for resilient cities. In: Lifelong Learning and Education in Healthy and Sustainable Cities. Edited by Azeiteiro UM, Akerman M, Filho WL, Setti AFF, Brandli LL. Cham, Switzerland: Springer International Publishing, 2018, pp. 355-376.

34. Ardoin NM, Bowers AW, Roth NW, et al. Environmental education and K-12 student outcomes: a review and analysis of research. J Environ Educ. 2018;49:1-17.

35. Hartig T, Mitchell R, de Vries S, et al. Nature and Health. Annu Rev Public Health. 2014;35:207.

36. Lachowycz K, Jones AP. Towards a better understanding of the relationship between greenspace and health: development of a theoretical framework. Landsc Urban Plan. 2013;118:62-69.

37. Sahin A, Ekmekci A, Waxman HC. The relationships among high school STEM learning experiences, expectations, and mathematics and science efficacy and the likelihood of majoring in STEM in college. Int J Sci Educ. 2017;39:1549-1572.

38. Lee K, Kim MJ, Park TH, et al. Effects of a ubiquitous mentoring program on self-esteem, school adaptation, and perceived parental attitude. Soc Behav Pers. 2015;43:1193-1208.

39. Strolin-Goltzman J, Woodhouse V, Suter J, et al. A mixed method study on educational well-being and resilience among youth in foster care. Child Youth Serv Rev. 2016;70:30-36.

40. Kern ML, Waters LE, Adler A, et al. A multidimensional approach to measuring well-being in students: application of the PERMA framework. J Posit Psychol. 2015;10:262-271.

41. Bratman GN, Hamilton JP, Daily GC. The impacts of nature experience on human cognitive function and mental health. Ann N Y Acad Sci. 2012; 1249:118-136.

42. Ekenga CC, Sprague N, Shobiye DM. Promoting health-related quality of life in minority youth through environmental education and nature contact. Sustainability. 2019;11:3544.

43. School Data. Missouri Department of Elementary \& Secondary Education. Available at https://dese.mo.gov/school-data Published 2019. Accessed February 10, 2020.

44. Ekenga CC, McElwain CA, Sprague N. Examining public perceptions about lead in school drinking water: a mixed-methods analysis of Twitter response to an environmental health hazard. Int J Environ Res Public Health. 2018;15:pii: E162.

45. Arroyo-Johnson C, Woodward K, Milam L, et al. Still separate, still unequal: social determinants of playground safety and proximity disparities in St. Louis. J Urban Health. 2016;93:627-638.

46. Metzger MW, Fowler PJ, Swanstrom T. Hypermobility and educational outcomes: the case of St. Louis. Urban Educ. 2018;53:774-805.

47. Gateway to the Great Outdoors. Available at https://www gatewayoutdoors.org Accessed September 9, 2019.

48. Missouri Learning Standards. Missouri Department of Elementary \& Secondary Education. Available at https://dese.mo.gov/college-careerreadiness/curriculum/missouri-learning-standards\#mini-panel-mlsstandards3 Published 2016. Accessed July 29, 2019. 
49. Lesson Plans, Teacher Guides and Online Environmental Resources for Educators. United States Environmental Protection Agency. Available at www.epa.gov/students/lesson-plans-teacher-guides-and-onlineenvironmental-resources-educators Accessed July 29, 2019.

50. Next Generation Science Standards: For States, By States. Achieve, Inc. Available at https://www.nextgenscience.org/ Accessed September 9, 2019.

51. Nelson E, Wasson J, Kirk J, et al. Assessment of function in routine clinicalpractice-description of the coop chart method and preliminary findings. J Chron Dis. 1987;40:S55-S63.

52. Nelson EC, Landgraf JM, Hays RD, et al. The functional status of patientshow can it be measured in physicians offices. Med Care. 1990;28:1111-1126.

53. Wasson JH, Kairys SW, Nelson EC, et al. A short survey for assessing health and social-problems of adolescents. J Fam Pract. 1994;38:489-494.

54. Morgan K, Barker B, Nugent G, et al. Educational Robotics as a Tool for Youth Leadership Development and STEM Engagement. Leiden, Netherlands: Brill Sense, 2019, p. 248.

55. Yan J, Li L, Yin J. Effects of MSTI summer camp program on students' perception on STEM learning. J STEM Educ Innov Res. 2020;20:1-14.

56. Falk JH, Staus N, Dierking LD, et al. Understanding youth STEM interest pathways within a single community: the Synergies project. Int J Sci Educ Part B. 2016;6:369-384.

57. DeCoito I. STEM education in canada: a knowledge synthesis. Can J Sci Math Technol Educ. 2016;16:114-128.

58. Drazan J, Loya A, Horne B, et al. From Sports to Science: Using Basketball Analytics to Broaden the Appeal of Math and Science Among Youth. Boston: MIT Sloan Sports Analytics Conference, 2017, pp. 1-16.

59. Price CA, Kares F, Segovia G, et al. Staff matter: gender differences in science, technology, engineering or math (STEM) career interest development in adolescent youth. Appl Dev Sci. 2019;23:239-254.

60. Waliczek TM, Logan P, Zajicek JM. Exploring the impact of outdoor environmental activities on children using a qualitative text data analysis system. Horttechnology. 2003;13:684-688.

61. Braun V, Clarke V, Weate P. Using thematic analysis in sport and exercise research. In: Routledge Handbook of Qualitative Research in Sport and Exercise. London: Taylor \& Francis (Routledge), 2016, pp. 191-205.

62. Clarke V, Braun V. Thematic analysis. J Posit Psychol. 2017;12:297-298.

63. Mackenzie SH, Son JS, Eitel K. Using outdoor adventure to enhance intrinsic motivation and engagement in science and physical activity: an exploratory study. J Outdo Recreat Tour. 2018;21:76-86.
64. Harper NJ. Wilderness therapy, therapeutic camping and adventure education in child and youth care literature: a scoping review. Child Youth Serv Rev. 2017;83:68-79.

65. Pate RR, Dowda M, Dishman RK, et al. Change in children's physical activity: predictors in the transition from elementary to middle school. Am J Prev Med. 2019;56:e65-e73.

66. Lerner RM, Bowers EP, Geldhof GJ, et al. Promoting positive youth development in the face of contextual changes and challenges: the roles of individual strengths and ecological assets. New Dir Youth Dev. 2012;2012: 119-128.

67. Onetti W, Fernandez-Garcia JC, Castillo-Rodriguez A. Transition to middle school: self-concept changes. PLoS One. 2019;14:e0212640 .

68. Freeman S, Eddy SL, McDonough M, et al. Active learning increases student performance in science, engineering, and mathematics. Proc Natl Acad Sci U S A. 2014;111:8410-8415.

69. White MP, Alcock I, Grellier J, et al. Spending at least 120 minutes a week in nature is associated with good health and wellbeing. Sci Rep. 2019;9: 7730 .

70. James JK, Williams T. School-based experiential outdoor education: a neglected necessity. J Exp Educ. 2017;40:58-71.

Cite this article as: Sprague N, Berrigan D, Ekenga CC (2020) An analysis of the educational and health-related benefits of naturebased environmental education in low-income black and Hispanic children, Health Equity 4:1, 198-210, DOI: 10.1089/heq.2019.0118.

$\begin{aligned} & \text { Abbreviations Used } \\ & \mathrm{GGO}=\text { Gateway to the Great Outdoors } \\ & \mathrm{HRQOL}=\text { health-related quality of life } \\ & \mathrm{LNT}=\text { Leave No Trace } \\ & \mathrm{NBE}=\text { nature-based education } \\ & \mathrm{SLPS}=\text { St. Louis Public School } \\ & \mathrm{STEM}=\text { science, technology, engineering, and math }\end{aligned}$

